\title{
recildunds
}

Revista Cientifica Mundo de la Investigación y el Conocimiento

Andrea Gabriela Cedeño Romero a; Angela María Fierro Guzñay b; Cristian Efraín Santillan Coello ${ }^{c}$; Tulio Andrés Jaramillo Peralta ${ }^{\mathrm{d}}$

Queratitis herpética. Diagnóstico y Tratamiento

Herpetic keratitis Diagnosis and treatment

Revista Científica Mundo de la Investigación y el Conocimiento. Vol. 3 núm. 4., diciembre, ISSN: 2588-073X, 2019, pp. 549-570

DOI: $10.26820 /$ recimundo/3.(4).diciembre.2019.549-570

URL: http://recimundo.com/index.php/es/article/view/681

Código UNESCO: 3205 Medicina Interna

Tipo de Investigación: Artículo de Revisión

(C) RECIMUNDO; Editorial Saberes del Conocimiento, 2019

Recibido: 15/09/2019

Aceptado: 23/11/2019

Publicado: 30/12/2019

Correspondencia: andreacedenior@gmail.com

a. Médico; Investigador Independiente; Guayaquil, Ecuador; andreacedenior@gmail.com

b. Médico; Investigador Independiente; Guayaquil, Ecuador; angelafierrog@ hotmail.com

c. Médico; Investigador Independiente; Guayaquil, Ecuador; csantillanczs5@gmail.com

d. Médico; Investigador Independiente; Guayaquil, Ecuador; tjaramillomd@gmail.com 


\section{Queratitis herpética. Diagnóstico y Tratamiento}

Vol. 3, núm. 4., (2019)

Andrea Gabriela Cedeño Romero; Angela María Fierro Guzñay; Cristian Efraín Santillan Coello; Tulio Andrés Jaramillo Peralta

\section{RESUMEN}

Mediante diversos estudios se ha evidenciado que una de las causas más recuentes en países desarrollados de ceguera infecciosa es la queratitis herpética. Esta se trata de una infección viral del ojo comúnmente causada por el virus del herpes simple (VHS) de los cual existen dos tipos, el tipo I, más común y afecta principalmente a la cara, y el tipo II, que es la forma de transmisión sexual del herpes, la cual infecta los genitales. Cualquiera de estos dos tipos de herpes pueden propagarse en los ojos y ocasionar una infección, siendo el de tipo I, generalmente, la causa de infecciones en los ojos. Mediante un diseño documental y una metodología de revisión, el objetivo del presente trabajo se centra en describir algunos de los aspectos más importantes de la queratitis herpética que ofrece la literatura actual. Los resultados radicaron en el establecimiento de algunos conceptos básicos, así como también de las causas, signos y síntomas, tipos, diagnóstico y tratamiento de la queratitis herpética. A través de la revisión de la literatura, finalmente se concluye que, lo encontrado sobre queratitis herpética sigue teniendo una gran incidencia en la población mundial, que su diagnóstico, en general, se ha mantenido dentro de los parámetros previamente establecidos por la práctica clínica en mayor proporción, y que, tanto los tratamientos ya adelantados como los que recientemente han surgido hacen posible que la morbilidad manifestadas en este tipo de pacientes pueda ser disminuida de manera significativa.

Palabras Claves: Infección; Cornea; Herpesvirus; Úlceras Dendríticas; Infección Resistente. 


\title{
Queratitis herpética. Diagnóstico y Tratamiento
}

Vol. 3, núm. 4., (2019)

Andrea Gabriela Cedeño Romero; Angela María Fierro Guzñay; Cristian Efraín Santillan Coello;

Tulio Andrés Jaramillo Peralta

\begin{abstract}
Various studies have shown that one of the most common causes in developed countries of infectious blindness is herpetic keratitis. This is a viral infection of the eye commonly caused by the herpes simplex virus (HSV) of which there are two types, type I, most common and mainly affects the face, and type II, which is the form of sexual transmission of herpes, which infects the genitals. Either of these two types of herpes can spread in the eyes and cause an infection, being type I, usually the cause of eye infections. Through a documentary design and a review methodology, the objective of this paper is to describe some of the most important aspects of herpetic keratitis offered by current literature. The results lay in the establishment of some basic concepts, as well as the causes, signs and symptoms, types, diagnosis and treatment of herpetic keratitis. Through the review of the literature, it is finally concluded that, what was found about herpetic keratitis continues to have a great impact on the world population, that its diagnosis, in general, has been maintained within the parameters previously established by clinical practice in higher proportion, and that, both the treatments already advanced and those that have recently emerged make it possible that the morbidity manifested in this type of patients can be significantly reduced.
\end{abstract}

Keywords: Infection; Cornea; Herpesvirus; Dendritic Ulcers; Resistant Infection. 


\section{Queratitis herpética. Diagnóstico y Tratamiento}

Vol. 3, núm. 4., (2019)

Andrea Gabriela Cedeño Romero; Angela María Fierro Guzñay; Cristian Efraín Santillan Coello; Tulio Andrés Jaramillo Peralta

\section{Introducción.}

Después del virus de la influenza y del resfriado común, una de las principales causas de enfermedad viral en humanos, en todo el mundo, son los herpesvirus. Cuando estos virus invaden el ojo humano se desarrolllan enfermedades cuyas complicaciones representan a nivel mundial una causa de morbilidad ocular importante.

La queratitis herpética es una infección viral del ojo causada más frecuentemente por el virus del herpes simple (VHS). Existen dos tipos principales de VHS, el tipo I que es el más común y afecta principalmente a la cara, causando el común "herpes labial" y el tipo II que es la forma de transmisión sexual del herpes, la cual infecta los genitales. Cualquiera de estos dos tipos de herpes pueden propagarse en los ojos y ocasionar una infección, siendo el de tipo I la causa más común de infecciones en los ojos. (Harrison \& Pagan, 2016)

Para Espinosa, Tandón, \& Medina (2016) el virus herpes simple (VHS) es uno de los virus que adquieren con más frecuencia los seres humanos. Se estima que por lo menos un $90 \%$ de la población adulta presenta anticuerpos positivos para el virus. "El VHS tipo 1 produce infecciones oculares con mayor frecuencia y su recurrencia es una de las principales causas de ceguera en países industrializados, mientras que las infecciones por el VHS tipo 2 suelen ser menos frecuentes, pero más graves." (p. 21)

García (2018) coincide con el anterior en que la queratitis herpética es muy común en los países desarrollados como una de las principales causas de ceguera infecciosa. Asimismo, resalta la estimación del impacto global de la enfermedad la cual se calcula de 1 a 1,5 millones de casos, no obstante, no se ha podido precisar el impacto real. Es posible que, en los países en desarrollo, 


\section{Queratitis herpética. Diagnóstico y Tratamiento}

Vol. 3, núm. 4., (2019)

Andrea Gabriela Cedeño Romero; Angela María Fierro Guzñay; Cristian Efraín Santillan Coello;

Tulio Andrés Jaramillo Peralta

esta enfermedad sea ocasionada principalmente por estrés, falta de acceso al tratamiento y mayor exposición a rayos ultravioleta. (p. 108, 109)

Además del virus del herpes simple (VHS), existen otros virus que originan la queratitis herpética como lo son el virus de la varicela zóster (VZV) y el citomegalovirus (CMV). Al respecto, Zhu \& Zhu (2014) refieren que el VZV en el ojo puede ocasionar una serie de manifestaciones oculares derivadas del herpes zoster oftálmico (HZO), con consecuencias graves que incluyen inflamación ocular crónica, pérdida de visión y dolor debilitante. Estas complicaciones generan una disminución considerable de la calidad de vida del paciente, además de un mayor uso de atención médica, dado que en promedio estas complicaciones duran más de 300 días. Por su parte el citomegalovirus (CMV) es el causante de enfermedad ocular en individuos inmunocomprometidos. La enfermedad intraocular más común en pacientes con síndrome de inmunodeficiencia adquirida (SIDA) es la retinitis por CMV, no obstante, esta enfermedad está aumentando su prevalencia en pacientes con función inmune normal. La retinitis por CMV, si no es diagnosticada y tratada a tiempo, puede conducir a la destrucción progresiva del tejido retiniano y pérdida visual irreversible. (p. 327, 328)

En razón de lo anterior, resulta fundamental un diagnóstico eficaz y precóz a los fines de precisar la patología presente y determinar el tratamiento oportuno y efectivo, así como el seguimiento del paciente mediante evaluaciones post tratamiento, a los fines de evitar reincidencia y las complicaciones que de esta se derivan. 


\section{Queratitis herpética. Diagnóstico y Tratamiento}

Vol. 3, núm. 4., (2019)

Andrea Gabriela Cedeño Romero; Angela María Fierro Guzñay; Cristian Efraín Santillan Coello; Tulio Andrés Jaramillo Peralta

En base a lo antes dicho, puede decirse que el objetivo de la presente iniciativa se centrará en el desarrollo de una investigación documental, delimitada a su vez a una metodología de revisión de la literatura, que se encuentre vigente y disponible en determinadas bases de datos, a fines de recabar las fuentes referenciales que conceptualmente expliquen de qué se trata la queratitis herpética, cuáles son sus tipos, sus causas, cómo se puede diagnosticar y tratarse.

\section{Materiales y Métodos.}

El presente trabajo se enmarca dentro de lo que se concibe como diseño documental, y la metodología escogida ha sido la de revisión, razones por las que, en síntesis, el enfoque del mismo es hacia la construcción de un material bibliográfico nuevo, en el que se procuró poner de manifiesto ideas vigentes de distintos autores en cuanto al diagnóstico y tratamiento de la queratitis herpética.

Se consultaron bases de datos tales como: Biblioteca Virtual de la Salud (BVS), SciELO, Medline Plus, BASE, Dialnet, National Institutes of Health (NHI), y otras. Como términos de búsqueda se utilizaron las expresiones "queratitis herpética", "herpes simple ocular" y "queratitis por herpes simple", a los que seguidamente se le aplicaron criterios de selección tales como: idiomas, español e inglés; periodo de publicación, entre 2009 y 2019, ambos inclusive, salvo algunas excepciones; tipo de acceso, completo y abierto; área, salud, medicina, humanos; tipo de bibliografía, artículos científicos, revisiones sistemáticas, guías clínicas, ebooks, ensayos clínicos, estudios de cohorte, estudios de casos, consensos, protocolos, tesis de grado, posgrado y doctorado, noticias científicas, boletines y/o folletos de instituciones oficiales o privadas de reconocida trayectoria en el área de la salud, medicina o cientificoacadémica, y demás, 


\section{Queratitis herpética. Diagnóstico y Tratamiento}

Vol. 3, núm. 4., (2019)

Andrea Gabriela Cedeño Romero; Angela María Fierro Guzñay; Cristian Efraín Santillan Coello;

Tulio Andrés Jaramillo Peralta

monografías y otros documentos que, a criterio del equipo, mostraran información de interés en base a la observación de la evidencia científica referida en sus contenidos. Este proceso arrojó resultados que en promedio oscilaron entre 7 y 88 enlaces a fuentes bibliográficas.

Igualmente, se llevaron a cabo otras pesquisas menores sin consideración de aplicar otros criterios de preselección, ya que se requirió encontrar información complementaria igualmente relevante para este tema. De allí en adelante, es entonces que el equipo procedió con la lectura crítica y análisis interpretativo de toda la información definitivamente recabada, la cual fue asumida como evidencia, resultando todo este proceso en la fundamentación del criterio aquí plasmado, por cierto, en todo momento hecho de manera consensuada.

Finalmente, es también destacable que, la exclusión e inclusión de cada una de las referencias hechas en la presente revisión se definió igualmente mediante el consenso grupal, y de la misma manera fueron resueltas las opiniones desiguales.

\section{Resultados.}

"La queratitis por herpes simple es una infección viral grave. Esta puede causar ataques repetitivos provocados por el estrés, la exposición a la luz solar o cualquier afección que disminuya la respuesta inmunitaria." (Enciclopedia Médica, 2019)

Para Roat (2018):

La queratitis por herpes simple es la infección corneana por el virus herpes simple. Puede afectar el iris. Los signos y síntomas incluyen sensación de cuerpo extraño, lagrimeo, fotofobia e hiperemia conjuntival. Las recurrencias pueden dar lugar a hipoestesia, ulceración, cicatrización 


\section{Queratitis herpética. Diagnóstico y Tratamiento}

Vol. 3, núm. 4., (2019)

Andrea Gabriela Cedeño Romero; Angela María Fierro Guzñay; Cristian Efraín Santillan Coello; Tulio Andrés Jaramillo Peralta

permanente de la córnea y disminución de la visión. El diagnóstico se basa en el aspecto típico de las úlceras corneanas dendríticas y a veces en los cultivos para virus. El tratamiento se realiza con agentes antivíricos tópicos y a veces, sistémicos.

\section{Causas}

De acuerdo con Harrison \& Pagan (2016) expertos revisores por la American Academy of Ophthalmology (AAO, por sus siglas en inglés), cerca de un 90\% de la población se encuentra expuesta a la infección por herpes de Tipo I, sobretodo en etapa infantil, de allí pues es fácil comprender que sea tan contagioso ya que su transmisión sea frecuentemente por el contacto con la piel de alguien que tiene el virus.

Después de una infección original, el virus permanece en estado latente, viviendo en las células nerviosas de la piel o los ojos. Una recurrencia puede ser activada de varias maneras, incluyendo: estrés; exposición al Sol; fiebre; trauma en el cuerpo (como una lesión o cirugía); menstruación; ciertos medicamentos. Una vez que el herpes simple está presente en el ojo, por lo general infecta a los párpados, la conjuntiva (la membrana delgada y transparente de mucosa que recubre el interior de los párpados y la parte blanca del ojo), y la córnea (la ventana transparente, en la parte anterior del ojo).

\section{Síntomas y Signos}

Roat (2018) se refiere a dos momentos de infección, primaria y recurrente, y además, explica lo relativo a la afectación del estroma. Al respecto dijo: 


\section{Queratitis herpética. Diagnóstico y Tratamiento}

Vol. 3, núm. 4., (2019)

Andrea Gabriela Cedeño Romero; Angela María Fierro Guzñay; Cristian Efraín Santillan Coello;

Tulio Andrés Jaramillo Peralta

La infección inicial (primaria) suele ser una forma inespecífica de conjuntivitis autolimitada que a menudo aparece en la primera infancia y habitualmente no se asocia con afectación corneana. Cuando está afectada la córnea, los primeros síntomas incluyen sensación de cuerpo extraño, lagrimeo, fotofobia e hiperemia conjuntival. A veces sigue una blefaritis vesiculosa (vesículas en los párpados), los síntomas empeoran, la visión se vuelve borrosa y las vesículas se rompen y se ulceran; luego desaparecen en el plazo de una semana sin dejar cicatriz. Las recurrencias habitualmente adoptan la forma de una queratitis epitelial (también llamada queratitis dendrítica) con lagrimeo, sensación de cuerpo extraño y una lesión ramificada característica (dendrítica o serpenteante) del epitelio corneano que se asemeja a una rama de árbol con botones terminales que se tiñen con fluoresceína. Las recurrencias múltiples pueden dar lugar a una hipoestesia o anestesia corneana, ulceración, cicatrización permanente de la córnea y disminución de la visión. La mayoría de los pacientes con queratitis disciforme, que afecta primariamente el endotelio corneano, tienen un antecedente de queratitis epitelial. La queratitis disciforme es un área localizada discoide más profunda de edema y opacidad corneana secundaria, acompañados por uveítis anterior. Esta forma puede producir dolor y pérdida de la visión reversible. La queratitis del estroma puede producir necrosis del estroma y dolor intenso, fotofobia, sensación de cuerpo extraño y deterioro irreversible de la visión.

Según Wang (2019) las siguientes manifestaciones son propias de la queratitis herpética: dolor, fotofobia, visión borrosa, lagrimeo y enrojecimiento. Así mismo expresa que: 


\section{Queratitis herpética. Diagnóstico y Tratamiento}

Vol. 3, núm. 4., (2019)

Andrea Gabriela Cedeño Romero; Angela María Fierro Guzñay; Cristian Efraín Santillan Coello; Tulio Andrés Jaramillo Peralta

El primer signo de replicación viral activa en el epitelio corneal es el desarrollo de vesículas pequeñas, elevadas y claras. Las úlceras dendríticas son la presentación más común de queratitis por HSV. Las características prominentes de una úlcera dendrítica incluyen un patrón de ramificación lineal con bulbos terminales en los extremos de las ramas, bordes epiteliales hinchados de las ramas y ulceración central a través de la membrana basal. Los primeros signos de queratopatía neurotrófica incluyen una superficie corneal irregular y erosiones epiteliales punteadas. Estas erosiones pueden progresar a un defecto epitelial persistente y ulceración estromal eventual. La queratitis estromal necrotizante se caracteriza por infiltrado estromal denso, ulceración y necrosis. La queratitis estromal inmune (ISK) puede presentarse clínicamente con infiltrados celulares focales, multifocales o difusos; anillos inmunes; neovascularización; o vasos fantasmas en cualquier nivel de la córnea. Los signos clínicos de endoteliitis incluyen precipitados queraticos (KP), edema estromal y epitelial suprayacente y ausencia de infiltrado estromal o neovascularización. Con frecuencia se observa una iritis leve a moderada. Los pacientes presentan dolor, fotofobia e inyección.

\section{Tipos de queratitis herpética}

- La epitelial, esta queratitis herpética se caracteriza por tener un tiempo de incubación entre 1 y 28 días, afectando únicamente al epitelio de la córnea. Cuando se presenta por primera, vez lo hace de manera leve y asintomática.

- La estromal inmune, que puede aparecer cuando ya se ha tenido un primer episodio o cuando se ha presentado de manera recurrente. Puede ser intersticial o disciforme.

- La estromal necrotizante: es la forma más grave y puede producir ceguera. (Servicio de 


\section{Queratitis herpética. Diagnóstico y Tratamiento}

Vol. 3, núm. 4., (2019)

Andrea Gabriela Cedeño Romero; Angela María Fierro Guzñay; Cristian Efraín Santillan Coello;

Tulio Andrés Jaramillo Peralta

Oftalmología del Hospital Universitario Sanitas La Moraleja, 2018)

En este sentido, García (2018) hace su diferenciación al referir que se puede presentar:

- Queratitis no necrotizante: Anteriormente conocido como queratitis inmune, ocurre en $20 \%$ de los casos de pacientes con enfermedad crónica o recurrente. En estos casos no hay historia de compromiso del epitelio y este se encuentra intacto. Se evidencia una inflamación estromal focal, multifocal o difusa que se puede asociar a uveítis anterior. La inflamación puede ser crónica, recurrente o recrudescente llevando a cicatrización estromal, adelgazamiento, neovascularización y depósito de lípidos. Ocasionalmente se observa un anillo inmune o anillo de Wessely, que representa el complemento de precipitado antígeno-anticuerpo.

- Endotelitis: La queratitis estromal se puede asociar a endotelitis la cual se puede presentar en tres formas: disciforme, difusa y linear. En la mayoría de casos es muy difícil diferenciar entre una inflamación estromal y un edema estromal secundario a una endotelitis. La forma más común es la disciforme la cual se caracteriza por una lesión en forma de disco central o paracentral que compromete todo el estroma corneal dando una apariencia de vidrio esmerilado, asociado a la presencia de precipitados queráticos e iritis leve a moderada. La forma linear se caracteriza por la presencia de precipitados queráticos en forma serpiginosa que progresan desde el limbo hacia el centro de la córnea asociado a edema estromal y epitelial. En la mayoría de las ocasiones se acompaña de una elevación de la presión intraocular, aparentemente por una trabeculitis.

- Síndrome iridocorneal endotelial: Se presenta de forma unilateral asociado a edema 


\section{Queratitis herpética. Diagnóstico y Tratamiento}

Vol. 3, núm. 4., (2019)

Andrea Gabriela Cedeño Romero; Angela María Fierro Guzñay; Cristian Efraín Santillan Coello; Tulio Andrés Jaramillo Peralta

corneal, corectopia y una alteración del trabéculo lo que genera un glaucoma secundario.

- Queratitis herpética en niños: La queratitis herpética en niños difiere de la de los adultos en cuanto a que la presentación es bilateral en 10 al 21\% de los casos y la respuesta inflamatoria es mucho mayor por lo que hay una mayor predisposición a la cicatrización corneal. (pág. 110-111)

\section{Diagnóstico}

El diagnóstico precoz y exacto permite establecer un tratamiento adecuado y evita las complicaciones de la queratitits herpética. Una adecuada atención médica aumenta las posibilidades de que estas infecciones puedan tratarse de manera exitosa. Asimismo, un adecuado seguimiento de la enfermedad, controla la reincidencia y la pérdida de visión a largo plazo.

Para Moya Ramírez (2015) las manifestaciones clínicas por infección primaria por VHS tipo 1 son raras, por lo general ocurren en tempranas épocas de la vida. Es típico que aparezcan como "una conjuntivitis que puede involucrar una blefaroconjuntivitis, marcada por vesículas y úlceras; que pueden incluir lesiones dendríticas en el epitelio corneal. Los pacientes con queratitis epitelial pueden presentar dolor, fotofobia, visión borrosa, lagrimeo y enrojecimiento". Por su parte, el virus de la varicela zóster (VZV) frecuentemente se diagnostica por la historia, la exploración y la clínica resultante. Resulta fundamental la apreciación de la aparición, distribución y aspecto característico de las lesiones, estas podrían ser suficientes para precisar un diagnóstico clínico. Sin embargo, existen circunstancias especiales que hacen recomendable que 


\section{Queratitis herpética. Diagnóstico y Tratamiento}

Vol. 3, núm. 4., (2019)

Andrea Gabriela Cedeño Romero; Angela María Fierro Guzñay; Cristian Efraín Santillan Coello;

Tulio Andrés Jaramillo Peralta

se ordenen algunas pruebas de laboratorio que permitan identificar el origen del proceso y establecer un diagnostico virológico preciso. (p. 15, 16)

El diagnóstico eficaz para detectar esta enfermedad resulta de gran importancia para determinar el tratamiento correspondiente. En virtud de que la queratitis herpética presenta una variedad de manifestaciones clínicas como se mencionó anteriormente, con diferentes cuadros clínicos, es importante su conocimiento y adecuado diagnóstico para no confundir la patología con cualquier otra enfermedad ocular con similares manifestaciones como es el caso de la conjuntivitis alérgica.

El diagnóstico general de la queratitis herpética suele incluir lo siguiente:

- Examen ocular. Si bien puede resultar incómodo abrir los ojos durante el examen, es importante que el médico pueda examinarlos. El examen incluirá una prueba que evalúa qué tan bien puedes ver (examen de agudeza visual).

- Examen con una minilinterna. El médico puede examinar tu ojo con una minilinterna para comprobar la reacción, el tamaño y otros factores de la pupila. El médico puede aplicar un tinte en la superficie del ojo para ayudar a identificar la extensión y el carácter de las irregularidades y las úlceras superficiales de la córnea.

- Examen con lámpara de hendidura. El médico te examinará los ojos con un instrumento especial llamado lámpara de hendidura. Proporciona aumento y una fuente de luz brillante para detectar el carácter y la extensión de la queratitis, así como el efecto que esta puede tener en otras estructuras del ojo. 


\section{Queratitis herpética. Diagnóstico y Tratamiento}

Vol. 3, núm. 4., (2019)

Andrea Gabriela Cedeño Romero; Angela María Fierro Guzñay; Cristian Efraín Santillan Coello; Tulio Andrés Jaramillo Peralta

- Análisis de laboratorio. El médico puede tomar una muestra de lágrimas o de algunas células de la córnea para hacer un análisis de laboratorio que determine la causa de la queratitis y ayude a elaborar un plan de tratamiento para esta enfermedad. (Mayo Clinic, 2019)

\section{Examen con lámpara de hendidura}

La lámpara de hendidura es un microscopio de bajo poder combinado con una fuente de luz de alta intensidad que puede enfocarse como un rayo delgado. Examina las estructuras que se encuentran en la parte frontal del ojo. El proveedor de atención médica examinará luego los ojos, especialmente los párpados, la córnea, la conjuntiva, la esclerótica y el iris. Con frecuencia, se utilizará un tinte amarillo (fluoresceína) para ayudar a examinar la córnea y la capa de lágrimas. El tinte se puede agregar ya sea como una gota para los ojos. O el proveedor puede tocar la esclerótica del ojo con una fina tira de papel teñida con el colorante. El tinte se enjuga por fuera de este con las lágrimas a medida que usted parpadea. Luego, se colocan gotas en los ojos para ensanchar (dilatar) las pupilas. Las gotas se demoran aproximadamente de 15 a 20 minutos para hacer efecto. Luego, se repite el examen con la lámpara de hendidura usando otro lente pequeño, sostenido cerca del ojo, de manera que se pueda evaluar la parte posterior de este. (Enciclopedia Médica, 2019)

Este examen permite al oftalmólogo acceder a una visión más cercana de todas las estructuras que conforman el ojo, tanto en su interior como al frente y en su parte posterior. Es por tanto un dispositivo clave en el diagnóstico de enfermedades oculares, entre ellas la queratitis herpética. 


\section{Queratitis herpética. Diagnóstico y Tratamiento}

Vol. 3, núm. 4., (2019)

Andrea Gabriela Cedeño Romero; Angela María Fierro Guzñay; Cristian Efraín Santillan Coello;

Tulio Andrés Jaramillo Peralta

\section{Pruebas de laboratorio}

Reacción en cadena de la polimerasa (PCR).

La PCR es un método de biología molecular que permite amplificar el material genético de tal forma que una pequeña porción de ADN es suficiente para detectar la presencia de bacterias y hongos. En una muestra obtenida por raspado palpebral se obtiene una cantidad de 3 a $6 \mathrm{ng} / \mu \mathrm{l}$ de $\mathrm{ADN}$ compuesto de una mezcla donde el mayor porcentaje proviene de las células del sujeto, mientras que en un raspado corneal la cantidad de ADN que se obtiene es menor, de 1 a 3ng/ $\mu$ l. En un paciente con infección ocular la cantidad de ADN obtenida sigue siendo la misma, pero el porcentaje de ADN proveniente de los microorganismos aumenta debido a la proliferación de los mismos en el sitio de la lesión, lo que hace posible su detección por PCR; utilizando los oligonucleótidos adecuados podemos amplificar e identificar si se trata de un hongo o una bacteria y, en caso de detectar un amplificado correspondiente a material genético bacteriano, es posible identificar si se trata de una bacteria grampositiva o gramnegativa usando la PCR anidada. Utilizando como base los trabajos de Jaegger et al. y Carrol et al.32,33 hemos logrado acortar el tiempo de duración de la PCR, obteniendo resultados en una sola ejecución utilizando una Tm en común para la detección de hongos y bacterias; esto es muy importante para el diagnóstico puesto que es un apoyo para la terapéutica oportuna y el restablecimiento de la salud del paciente. (Pérez Cano, 2014, pág. 70)

\section{Tratamiento}

Retomando el aporte de García (2018) es valioso destacar que este explica que: 


\section{Queratitis herpética. Diagnóstico y Tratamiento}

Vol. 3, núm. 4., (2019)

Andrea Gabriela Cedeño Romero; Angela María Fierro Guzñay; Cristian Efraín Santillan Coello; Tulio Andrés Jaramillo Peralta

En la década de los noventa se realizaron varios estudios conocidos como los HEDS (Herpetic Eye Disease Study), que al día de hoy siguen siendo el patrón de referencia en el tratamiento de la enfermedad herpética del segmento anterior. En cuanto a la queratitis herpética se ha visto una recuperación espontánea en el $50 \%$ de los pacientes, sin embargo, cuando se adiciona tratamiento con antivirales lo que se busca es disminuir la sintomatología, la pérdida visual y la tasa de recurrencia. [...] En el manejo de la queratitis estromal se recomienda el manejo combinado con corticoesteroides tópicos y antivirales tópicos como el Ganciclovir ungüento [...] En los estudios HEDS se evidenció que los pacientes que recibieron corticoides en la queratitis estromal presentan una reducción del 68\% de la progresión de la enfermedad porque suprimen la inflamación interfiriendo con los linfocitos B pero este efecto se mantiene sólo mientras dura el tratamiento por lo que su dosificación debe disminuir gradualmente para evitar la reactivación temprana. Igualmente se observó en estos casos que el Aciclovir por vía oral a una dosis de $400 \mathrm{mg} 5$ veces al día por 10 semanas no mejora el cuadro en cuanto a tiempo de resolución y agudeza visual al final del tratamiento. [...] En el caso de la queratitis necrotizante donde existe el riesgo de úlcera corneal y perforación, el tratamiento se realiza con antivirales orales y tópicos junto con corticoides, pero se deben tener en cuenta métodos de contención tectónico para el cierre como lo es el uso de cianoacrilato en perforaciones menores de $3 \mathrm{~mm}$ deteniendo el melting corneal a través de su acción bacterioestática contra gram positivos, la inhibición de polimorfonucleares y las enzimas proteolíticas. Si los defectos son mayores a $3 \mathrm{~mm}$ o no hay una respuesta al cianoacrilato, se puede utilizar la membrana amniótica que da un soporte estructural gracias al colágeno, la laminina, la fibronectina y los factores de crecimiento neural y epitelial que facilitan la adhesión y migración epitelial. Igualmente, el estroma de la 


\section{Queratitis herpética. Diagnóstico y Tratamiento}

Vol. 3, núm. 4., (2019)

Andrea Gabriela Cedeño Romero; Angela María Fierro Guzñay; Cristian Efraín Santillan Coello;

Tulio Andrés Jaramillo Peralta

membrana amniótica contiene metaloproteinasas y receptores antagonistas de interleukina 1 y anti VEGF que suprimen la infl amación y la angiogénesis. El flap conjuntival pediculado y la tarsorrafia son dos procedimientos adicionales de los cuales disponemos cuando no hay respuesta a ninguno de los tratamientos anteriormente descritos, promoviendo un ambiente ideal donde se puedan reclutar factores de crecimiento vitales y nutrientes que permitirán eliminar las proteasas proinflamatorias permitiendo una reepitelización rápida con células epiteliales corneales. Para los casos de queratopatia neurotrófica, desde 2009 se ha descrito un nuevo procedimiento denominado neurotización corneal, donde se busca realizar una reinervación de la córnea restaurando la sensibilidad corneal. [...] Por último, cabe destacar que en el 2017 la Comisión Europea de Medicamentos y en el 2018 la FDA autorizaron el uso de Cenegermin que es una forma recombinante del factor de crecimiento neural (NGF), presente en la superfi cie ocular, esencial para el crecimiento y mantenimiento de las neuronas simpáticas y sensitivas de la córnea. En las últimas dos décadas se han realizado estudios fase I fase II y fase III en aproximadamente 160 individuos con queratopatía neurotrófi ca secundaria a infección por Herpes Simplex, a quienes se les administró el medicamento a una concentración de 20Ug/ml 6 veces al día por 8 semanas, al cabo de las cuales se evidenció una adecuada reepitelización, transparencia y restauración de la sensibilidad corneal en casi la totalidad de ellos. Con la aprobación de este medicamento para su uso comercial se inicia el estudio fase IV que permitirá determinar la verdadera efectividad y posibles efectos adversos del Cenergermin en el tratamiento de la queratopatía neurotrófica (pág. 111-113) 


\section{Queratitis herpética. Diagnóstico y Tratamiento}

Vol. 3, núm. 4., (2019)

Andrea Gabriela Cedeño Romero; Angela María Fierro Guzñay; Cristian Efraín Santillan Coello; Tulio Andrés Jaramillo Peralta

Tabla 1. Antivirales tópicos y orales para Queratitis herpética

\begin{tabular}{|c|c|c|c|c|}
\hline Uso & $\begin{array}{l}\text { Medicamento / } \\
\text { Concentración }\end{array}$ & Queratitis epitelial & Queratitis estromal & Profilaxis \\
\hline & $\begin{array}{c}\text { Aciclovir ungüento } \\
3 \%\end{array}$ & 5 veces al día por 7-10 días. & & \\
\hline Tópico & $\begin{array}{c}\text { Ganciclovir gel } \\
0.15 \%\end{array}$ & $\begin{array}{l}\text { - } 5 \text { veces al día hasta } \\
\text { reepitelización. } \\
\text { - luego } 3 \text { veces al día por } 7 \\
\text { días. }\end{array}$ & & \\
\hline \multirow[t]{2}{*}{ Oral } & Aciclovir & 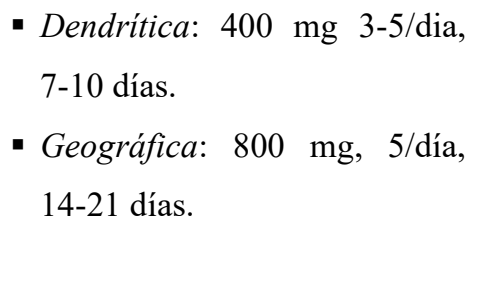 & $\begin{array}{l}\text { - Sin úlcera:400mg } 2 \text { día, 7-10 } \\
\text { días. } \\
\text { - Con úlcera: } 800 \mathrm{mg}, 3-5 / \text { día, } \\
\text { 7-10 días } \\
\text { - Endotelitis:400mg, 3-5/día }\end{array}$ & $\begin{array}{l}400 \text { mg } \\
\text { 2/día, } 1 \\
\text { año. }\end{array}$ \\
\hline & Valaciclovir & $\begin{array}{l}\text { - Dendrítica: 500mg, 2/día, } 7 \text { - } \\
10 \text { días. } \\
\text { - Geográfica:1 g, 3/día, 14-21 } \\
\text { días. }\end{array}$ & $\begin{array}{l}\text { - Sin úlcera: 500mg,1/día. } \\
\text { - Con úlcera: } 1 \text { g, 3/día, 7-10 } \\
\text { días } \\
\text { - Endotelitis: 500mg, 2/día. }\end{array}$ & $\begin{array}{l}\text { 500mg } \\
\text { 1/día } \\
\text { por un } \\
\text { año. }\end{array}$ \\
\hline
\end{tabular}

Nota: Adaptado de "Queratitis por herpes simple: revisión de literatura". García, F. (2018). Revista de la Sociedad Colombiana de Oftalmología. Vol. 51 (2): 111-112.

Ahora bien, Parro et al. (2018) indican otra forma de trata esta complicación cuando se está en presencia de "una infección resistente" al aciclovir, y su consecuente ganciclovir. Se refieren al uso de foscarnet en forma de colirio, el cual, según estos, se elabora "en los servicios de farmacia hospitalarios".

Los referidos tratadistas exponen que: 


\section{Queratitis herpética. Diagnóstico y Tratamiento}

Vol. 3, núm. 4., (2019)

Andrea Gabriela Cedeño Romero; Angela María Fierro Guzñay; Cristian Efraín Santillan Coello;

Tulio Andrés Jaramillo Peralta

La resistencia a aciclovir en el tratamiento de la queratitis herpética es una preocupación debido a que es la primera línea de tratamiento y profilaxis a largo plazo. Aunque no hay mucha bibliografía publicada acerca del tratamiento de la queratitis herpética resistente a aciclovir, diversos estudios muestran que el riesgo de resistencia no es mayor en aquellos pacientes tratados previamente con aciclovir, sino que serían mutaciones en diversos genes los que confieren el fenotipo resistente a aciclovir y ganciclovir. Choong et al. afirman que la terapia tópica con foscarnet es potencialmente efectiva para el tratamiento de la queratitis por VHS resistente a aciclovir y ganciclovir. En nuestra serie de casos, el tratamiento tópico con foscarnet demostró ser eficaz para el tratamiento agudo de la infección. Además, existen estudios de casos graves en los que se utiliza con éxito la terapia sistémica y tópica combinada. [...] En conclusión, el tratamiento de la queratitis por VHS resistente a aciclovir y ganciclovir con foscarnet colirio 2,4 $\mathrm{mg} / 0,1 \mathrm{ml}$ resulta eficaz para el tratamiento agudo de la infección, mejorando la sintomatología y con ausencia de toxicidad. Sin embargo, no evita las recurrencias por reactivación del VHS una vez finalizado el tratamiento. (pág. 334)

\section{Conclusión.}

Es evidenciable que las múltiples investigaciones sobre la queratitis herpética siguen favoreciendo una mayor comprensión de esta patología, no obstante, todo no está dicho en este tema.

Cabe destacar que la queratitis es una de las varias enfermedades que produce el herpesvirus (herpes simple), pero que con repetidas infecciones puede causar una enfermedad 


\section{Queratitis herpética. Diagnóstico y Tratamiento}

Vol. 3, núm. 4., (2019)

Andrea Gabriela Cedeño Romero; Angela María Fierro Guzñay; Cristian Efraín Santillan Coello; Tulio Andrés Jaramillo Peralta

visual debido a una cicatrización, adelgazamiento, neovascularización corneal y eventual ceguera.

Aunque las lesiones de párpado y córnea son muy evidentes y característicos, constatables mediante un examen físico, se vuelve muy importante, siempre que sea posible, aislar e identificar el HSV-1 para especificar el virus y poder comprobar algún tipo de mutación, superinfección por otra cepa u otras condiciones similares. De hecho, clasificar una queratitis favorece la adecuación del tratamiento, bien sea para el uso de antivirales orales, tópicos, corticoesteroides, debridamiento e inclusive trasplante corneal, todo ello dependiendo del tipo de queratitis.

\section{Bibliografía.}

Enciclopedia Médica. (02 de Diciembre de 2019). Examen con lámpara de hendidura. Recuperado el 28 de Diciembre de 2019, de medlinePlus.gov/spanish: https://medlineplus.gov/spanish/ency/article/003880.htm

Enciclopedia Médica. (02 de 12 de 2019). Úlceras e infecciones corneales. (U. N. Medicine, Editor) Recuperado el 20 de 12 de 2019, de medlineplus.gov: https://medlineplus.gov/spanish/ency/article/001032.htm

Espinosa, G., Tandón, L., \& Medina, F. (2016). Queratitis estromal necrotizante por virus herpes simple: A propósito de un caso. Archivo Sociedad Canaria de Oftalmología, 27, 20-23. $\begin{array}{llllll}\text { Recuperado el } 28 \text { de } & \text { Diciembre }\end{array}$ http://sociedadcanariadeoftalmologia.com/wp-content/revista/revista-27/27sco07.pdf

García, F. (2018). Queratitis por herpes simple: revisión de literatura. Revista de la Sociedad Colombiana de Oftalmología, 51(2), 105-114. Recuperado el 29 de Diciembre de 2019, de https://scopublicaciones.socoftal.com/index.php/SCO/article/view/232/207

Harrison, D. A., \& Pagan, B. (01 de Marzo de 2016). Academia Americana de Oftalmología. Recuperado el 21 de diciembre de 2019, de https://www.aao.org/saludocular/enfermedades/queratitis-herpetica 


\section{Queratitis herpética. Diagnóstico y Tratamiento}

Vol. 3, núm. 4., (2019)

Andrea Gabriela Cedeño Romero; Angela María Fierro Guzñay; Cristian Efraín Santillan Coello;

Tulio Andrés Jaramillo Peralta

Mayo Clinic. (05 de Febrero de 2019). Queratitis. Recuperado el 28 de Diciembre de 2019, de https://www.mayoclinic.org/es-es/diseases-conditions/keratitis/diagnosis-treatment/drc20374114

Moya Ramírez, R. E. (2015). QUERATITIS EPITELIAL HERPÉTICA. Tesis de Grado, UNIVERSIDAD TÉCNICA DE AMBATO, FACULTAD DE CIENCIAS DE LA SALUD, Ambato. Recuperado el 29 de Diciembre de 2019, de https://repositorio.uta.edu.ec/jspui/bitstream/123456789/14030/2/QUERATITIS\%20EPI TELIAL\%20HERPETICA.pdf

Parro, M., Sánchez, M., Pueyo, C., Gómez de Salazar, E., Arnalich, F., \& Bermejo, T. (2018). Tratamiento de la queratitis herpética resistente a aciclovir y ganciclovir: a proposito de una serie de casos. OFIL.ILAPHAR, 28(4), 333-334. Recuperado el 20 de 12 de 2019, de http://www.revistadelaofil.org/wp-content/uploads/2018/11/Caso-Clinico-2-OFIL-284.pdf

Pérez Cano, H. J. (2014). Establecimiento de una reacción en cadena de la polimerasa para la detección de bacterias y hongos. Revista Mexicana de Oftalmología, 88(2), 67-72. Recuperado el 29 de diciembre de 2019, de https://www.elsevier.es/es-revista-revistamexicana-oftalmologia-321-articulo-establecimiento-una-reaccion-cadena-polimerasaS0187451914000043

Roat, M. (Agosto de 2018). Queratitis por herpes simple. Recuperado el 20 de 12 de 2019, de msdmanuals.com: $\quad$ https://www.msdmanuals.com/es/professional/trastornosoft\%C3\%A1lmicos/enfermedades-de-la-c\%C3\%B3rnea/queratitis-por-herpes-simple

Servicio de Oftalmología del Hospital Universitario Sanitas La Moraleja. (30 de Abril de 2018). Sanitas. Recuperado el 20 de 12 de 2019, de tusdudasdesalud.com: https://tusdudasdesalud.com/vision/enfermedades-ojo/queratitisherpetica/\#Tipos_de_queratitis_herpetica

Wang, J. (18 de Enero de 2019). Medscape. Recuperado el 20 de 12 de 2019, de https://emedicine.medscape.com: https://emedicine.medscape.com/article/1194268overview

Zhu, L., \& Zhu, H. (2014). Ocular herpes: the pathophysiology, management and treatment. Virológica SINICA, 29(6), 327-342. Recuperado el 20 de diciembre de 2019, de https://link.springer.com/content/pdf/10.1007/s12250-014-3539-2.pdf 
Queratitis herpética. Diagnóstico y Tratamiento

Vol. 3, núm. 4., (2019)

Andrea Gabriela Cedeño Romero; Angela María Fierro Guzñay; Cristian Efraín Santillan Coello; Tulio Andrés Jaramillo Peralta

$$
\text { (c) (i) () (9) }
$$

RECONOCIMIENTO-NOCOMERCIAL-COMPARTIRIGUAL

CC BY-NC-SA

ESTA LICENCIA PERMITE A OTROS ENTREMEZCLAR, AJUSTAR Y CONSTRUIR A PARTIR DE SU OBRA CON FINES NO COMERCIALES, SIEMPRE Y CUANDO LE RECONOZCAN LA AUTORIIA Y SUS NUEVAS CREACIONES ESTÉN BAJO UNA LICENCIA CON LOS MISMOS TÉRMINOS. 